\title{
The role of androgens in experimental rodent mammary carcinogenesis
}

\author{
Jaesung Choi, Basil Psarommatis, Yan Ru Gao, Yu Zheng, David J Handelsman* and Ulla Simanainen
}

\begin{abstract}
Breast cancer is currently the most frequent, fatal cancer of women in western countries. While estrogens have a widely understood involvement in breast cancer, a significant but not yet fully understood role for androgens has also been suggested. The principal androgen, testosterone, is the obligate steroidal precursor of estradiol, but can equally be metabolized into dihydrotestosterone, a more potent, pure androgen. Both androgens exert their distinctive biological effects via the androgen receptor, which is coexpressed with estrogen receptor alpha in 80 to $90 \%$ of breast cancers. The hormonal control of breast development and pathology has been examined experimentally through the use of animal models, notably mice and rats. This review summarizes the data from experimental rodent models on the effects of androgens in experimental breast cancer, aiming to address the importance of androgens and the androgen receptor in the origins and pathogenesis of breast cancers, as well as to discuss potential biomarker and therapeutic opportunities arising from novel insights based on the experimental research.
\end{abstract}

\section{Introduction}

Breast cancer is currently among the most frequent and fatal cancers afflicting women worldwide. The strongest epidemiological clues to the hormonal origins of breast cancer arise from the recognition of lifetime endogenous estrogen exposure comprising early menarche, incessant ovulation, and late first lactation and menopause. While estrogens have a widely understood involvement, we [1] and others (reviewed in [2]) have demonstrated a significant but not yet fully understood role for androgens in breast cancer. The hormonal control of breast

\footnotetext{
* Correspondence: djh@anzac.edu.au

ANZAC Research Institute, University of Sydney, Sydney, NSW 2139, Australia
}

development and pathology has been examined through animal model experimentation, most frequently involving mice and rats.

This review summarizes the experimental data using rodent models on the effects of androgens in experimental breast cancer, aiming to highlight the role of androgens and androgen receptor (AR)-mediated androgen effects in experimental breast cancers. In addition, the review aims to lay a solid foundation for a consensus, as well as guidance for future research into novel biomarkers and therapeutic targets arising from novel insights acquired from experimental research. Owing to increased interest in androgen actions in breast cancer, we will cover the historical aspects briefly, but concentrate on the most recent literature focusing on the role of androgens in experimental rodent breast tumorigenesis. This focus on experimental animal models aims to provide a complementary view to recent reviews of androgens and breast cancer, which concentrate on clinical data and human breast cancer cell lines $[2,3]$.

\section{Androgens, androgen receptor and breast cancer Androgens and the androgen receptor}

Androgens are a group of 19-carbon steroid hormones produced mainly in the testes, but to a lesser extent in other steroidogenic tissues such as ovaries, adrenal glands, and placenta, as well as in peripheral tissues, including adipose tissue and mammary glands. Dehydroepiandrosterone (DHEA) and androstenedione are pro-androgens (androgen precursors) capable of being converted into testosterone and/or dihydrotestosterone (DHT) in peripheral and androgen target tissues. The major circulating androgen, testosterone, either can be aromatized (via aromatase enzyme) into estradiol $\left(E_{2}\right)$ acting via estrogen receptor (ER) signaling or can be reduced (via $5 \alpha$-reductases) within target tissues to the nonaromatizable androgen DHT, which has higher androgenic bioactivity than testosterone and is associated with a higher affinity for AR [4], leading to more potent androgen signaling. While DHT is a 
nonaromatizable androgen, it can be further reduced irreversibly to $3 \beta$-androstanediol that may activate $\operatorname{ER} \beta$ [5].

Androgens (testosterone, DHT) and pro-androgens (DHEA, androstenedione) are the most abundant sex hormones produced in women, with the normal ovary producing larger amounts of androgens than $\mathrm{E}_{2}$; however, $E_{2}$ is two orders of magnitude more potent on a molar basis than testosterone or DHT. Testosterone serves as an obligate precursor for $\mathrm{E}_{2}$ synthesis, so androgens play an indirect but necessary role in female physiology. Yet ARs are also expressed in virtually every tissue in women, including breast tissue, suggesting a direct physiological role for the AR-mediated androgen effects [6].

Evidence for the role of androgens in human breast cancer Significant roles for androgens in human breast cancer susceptibility and as treatment options have received more attention recently. The AR is expressed in 70 to $90 \%$ of breast cancers, comparable with ER $\alpha$ (70 to $80 \%$ ) and progesterone receptor (50 to $70 \%$ ) positivity. Yet ARnegative breast cancers respond poorly to hormone therapy with reduced overall survival, while conversely AR-positive cancers are smaller with fewer lymph node metastases corresponding to a better prognosis, thus demonstrating the role of the AR as a biomarker [7]. Importantly, AR expression is detected in about 10 to $50 \%$ of triple-negative (ER, progesterone receptor and Her-2) breast cancers that respond poorly to traditional therapies (reviewed in [3]). Similarly, natural models of high endogenous androgen exposure - such as women suffering from polycystic ovarian syndrome and congenital adrenal hyperplasia, as well as men with much lower risk of breast cancer when compared with women - support the concept that androgen action may protect against breast cancer $[8,9]$.

\section{Rodent breast cancer models}

The history of experimental breast cancer has been reviewed extensively [10], and therefore our aim is to concisely describe the models used to explore the role of androgens in experimental rodent breast cancers.

\section{Chemical carcinogenesis}

One of the most remarkable findings in breast cancer research is the ability to induce breast-specific tumors in rodents, usually not susceptible to spontaneous breast cancer, using chemical carcinogens [11]. Common molecular mechanisms that possibly underlie chemical carcinogenesis involve activating mutations of ras proto-oncogenes [12]. Interestingly, the activation of ras proto-oncogenes following chemical carcinogenesis could be regulated by other signaling pathways. This hypothesis was demonstrated by a lack of $\mathrm{H}$-ras-activating mutations and upregulation at the expression level following 7,12-dimethylbenz(a)anthracene (DMBA)-induced skin carcinogenesis in PTEN knockout mice [13]. Similarly, androgens acting via AR could regulate ras proto-oncogene activation in chemical carcinogenesis as supported in hormonally induced prostate cancer [14]. Androgens could therefore modify carcinogeninduced mammary tumors either by directly regulating proliferation and cell cycle via targeting growth factors or by the regulation of underlying molecular mechanisms in chemical carcinogenesis.

\section{Dimethylbenz(a)anthracene and methylcholanthrene}

Most early research examining the role of androgens in carcinogen-induced experimental breast cancer used methylcholanthrene (MCA) [15,16]. But DMBA has become the current mainstay because only a single dose is required to induce mammary tumors in $100 \%$ of female rats with a mean time of 95 days (reviewed in [17]). DMBA and MCA are polycyclic aromatic hydrocarbons that act through the aryl hydrocarbon receptor. They are also procarcinogens requiring cytochrome P450 (1A1, 1A2 and 1B1) activation to become carcinogens and subsequently form metabolite-DNA adducts. Aryl hydrocarbon receptor activation transcriptionally regulates cytochrome P450 (CYP) enzymes, but can also act directly by regulating cell growth, apoptosis, and transition to an invasive, metastatic phenotype [18]. Aryl hydrocarbon receptor activation and inducible CYP systems are therefore central to chemical carcinogenesis induced by polycyclic aromatic hydrocarbons, a process that may be susceptible to regulation by androgens $[19,20]$. DMBA treatment also induces ovarian damage characterized by small afollicular ovaries and reduced circulating androgens $[1,21]$, but with increased circulating follicle-stimulating hormone and luteinizing hormone [1]. This damage is more prominent in mice than rats, which may contribute to mice having a greater susceptibility to DMBA-induced mammary tumors.

\section{$\mathrm{N}$-Nitroso-N-methylurea}

In contrast to DMBA and MCA, $N$-nitroso- $N$-methylurea is a direct-acting carcinogen that does not require metabolic activation. This carcinogen can be advantageous in experiments that involve co-treatments or genetic modification, which may influence CYP activation [16].

\section{Hormonal carcinogenesis}

Spontaneous breast cancer is very rare in rodents and therefore hormonal treatments are required to induce breast cancers (early work extensively reviewed in [22]). Long-term continuous exposure to exogenous $E_{2}$ or the pro-estrogen estrone $\left(\mathrm{E}_{1}\right)$ in rats induces a high incidence of mammary tumors that frequently metastasize. Tumor latency depends on the estrogen dose as well as 
the rat strain and age [22]. The mechanisms suggested for estrogen-induced carcinogenicity include activation of ER signaling pathways [23] or the metabolism of estrogen into oxidative metabolites having genotoxic, mutagenic, transforming, and carcinogenic effects [24]. Androgen actions could therefore either modify ER-dependent signaling [25] or the metabolism of $E_{2}$ and $E_{1}$ by P450 enzymes [26]. Administration of either natural (progesterone) or synthetic (medroxyprogesterone acetate) progestins increases the carcinogen-induced mammary tumor incidence in mice [27]. Medroxyprogesterone acetate may function as a promoter for DMBA-induced carcinogenesis or by increasing the incidence of DMBA-induced mutations involving the $\mathrm{H}$-ras proto-oncogene [27]. However, it is important to note that medroxyprogesterone acetate is also a potent activator of AR [28].

\section{Spontaneous carcinogenesis}

Some specific rodent strains are highly prone to spontaneous mammary tumor formation. Spontaneous mammary tumors occur over a range from $40 \%$ for Fischer rats to over $80 \%$ for Buff/N rats [29]. Similarly the $\mathrm{C} 3 \mathrm{H}$ mouse strain with a high lifetime incidence $(>70 \%)$ of mammary tumors has been used to study androgen effects on mammary tumors [30]. Mammary tumors in $\mathrm{C} 3 \mathrm{H}$ mice are mainly due to the presence of mouse mammary tumor viruses that induce tumors by acting as insertional mutagens, which in turn activates the expression of cellular proto-oncogenes. Viral transcription is regulated by specific sequences within the long terminal repeat that are also responsive to androgen action [31] and could modify the initiation of tumors, but cannot explain the androgen effect on existing tumors. Rat and mouse lines differing in their sensitivity to spontaneous mammary tumors have been used to determine genetic components, including dominant resistance genes as well as sensitivity genes that modify susceptibility to spontaneous and/or induced mammary tumors and could be shared by human tumors.

\section{Genetically modified mouse models}

The development of genetically modified, transgenic or knockout, mouse models has greatly advanced our understanding of the molecular basis of initiation, promotion, and progression of breast cancer. Numerous genetic mouse models used in breast cancer studies include APC, BRCA1, ERBB2 (Neu), p53, and PTEN knockout mouse models (reviewed in [10]). Mammary gland-specific, targeted inactivation of relevant genes such as the $\mathrm{Ar}$ (CreloxP using promoters targeting mammary cells; Table 1) combined with breast cancer models are promising approaches to investigate androgenic regulation of specific pathways and effects on mammary gland pathology [32].

$\begin{aligned} & \text { Table } \mathbf{1} \text { Promoters driving transgene expression in } \\
& \text { mammary cells }\end{aligned}$
\begin{tabular}{lll} 
Promoter & Origin & Expression \\
\hline MMTV-LTR & Mouse mammary tumor virus & $\begin{array}{l}\text { Breast epithelial cells, } \\
\text { several other tissues }\end{array}$ \\
WAP & Whey acidic protein & $\begin{array}{l}\text { Secretory mammary } \\
\text { epithelium }\end{array}$ \\
C3(1) & $\begin{array}{l}\text { Rat prostate steroid-binding } \\
\text { protein }\end{array}$ & $\begin{array}{l}\text { Epithelial cells of prostate } \\
\text { and mammary gland }\end{array}$ \\
B-LG & Bovine $\beta$-lactoglobulin & Mammary gland \\
MT & Metallothionein & Most mammary cells
\end{tabular}

\section{Relevance of rodent breast cancer models to human breast cancer}

Rodent models are irreplaceable for exploring the in vivo biology and mechanisms of tumor initiation, promotion, progression, and metastasis. These models provide unique help to identify otherwise unrecognized opportunities for novel treatment and diagnostic or prognostic markers through experiments not feasible in humans. Mammary tumors in rodents and humans display many etiological similarities. In both species, spontaneous tumors develop late in life and with low frequency, while genetic factors increase both the susceptibility and frequency of but reduce the latency of overt tumors ([33]; see Androgens and spontaneous rodent carcinogenesis). Furthermore, hormonal induction of breast cancer is directly proven in rodent models and is a well-accepted inference in human breast cancers from large observational studies of estrogentreated women [34]. Similarly, carcinogen-induced experimental breast cancer is proven in rodents (for example, polycyclic aromatic hydrocarbons) and is suspected (see Androgens and chemical carcinogenesis) but less clearly established in human breast cancers. While no single rodent model can address all aspects of human breast cancer, different experimental models provide complementary findings to decipher the heterogeneity of established but fragmentary pathophysiological knowledge currently available. The evaluation of experimental breast cancer model(s), while quite germane to human breast cancer, must therefore consider critically the appropriate caveats on the design and interpretation of findings for such species extrapolation.

Different experimental breast cancer models have distinct features that should be considered in choosing an optimal model for the study of interest. Considerations should include histological similarities as well as the degree of genetic or transcriptomic similarity (including steroid hormone receptor expression and hormone sensitivity). Although it is desirable to use similar morphological descriptors to describe human and rodent mammary tumors, the morphology of rodent tumors is quite distinctive and trained pathologists would not confuse them with human tumors [35]. For example, the main histotypes in 
DMBA-induced mouse mammary tumors are carcinomas/ adenocarcinomas or squamous cell carcinomas [1], while the latter are very rare in women [36]. On the other hand, spontaneous tumors tend to have hyperproliferation of both connective and glandular tissues and are generally classified as fibroadenomas [37].

Interestingly, while mammary tumor development in rodents and women is highly estrogen dependent [38], rat mammary tumors are mainly estrogen responsive whereas mouse mammary tumors are mainly estrogen independent, with human breast cancers falling between rat and mouse tumors with regard to estrogen sensitivity [38]. To integrate the estrogen-independent mammary tumors in mice into a more estrogen-sensitive framework, specific ER-positive mammary tumor mouse models have been developed (references cited in [39]) and we found that DMBA generates both ER $\alpha$-positive and ER $\alpha$-negative tumors in mice [1]. These ER-positive models could therefore be used to test the possible modifying effect of androgens on ER $\alpha$-dependent effects in breast cancer [25].

The transcriptomic similarity of human breast cancers and experimental mammary tumors in mouse models has been analyzed recently [39]. Where some models developed tumors with model-specific gene expression and histopathological patterns (for example, TgC3(1)-Tag model) suitable for specific mechanistic studies, others had greater diversity of tumors (for example, DMBA) [39]. Like human breast cancers, mouse mammary tumors can also be divided into basal or luminal types of clusters although luminal tumors with estrogen responsiveness and $E R \alpha$ positivity are less common in mice compared with women [39].

Rodent breast cancer models have the advantage of being able to produce a wide variety of breast cancer subtypes that are observed in breast cancer patients. Hence, using a judicious choice of rodent models allows researchers to investigate different subtypes of breast cancer by creating specific opportunities as a platform to study underlying biological mechanisms of mammary carcinogenesis, which cannot be directly investigated in humans. With the appropriate design of experiments as well as careful selection of experimental models, rodent models allow the identification of basic processes in breast cancer development, but also the means to test the roles of specific pathways as well as potential preventive and curative agents.

\section{Effects of androgens in rodent breast cancer models Androgens and chemical carcinogenesis}

Chemical carcinogens, notably DMBA, MCA, and Nnitroso- $N$-methylurea, have been widely used in experimental studies to explore the role of androgens in breast cancer since the mid twentieth century (Tables 2, 3 and 4).
The chemical carcinogen studies are categorized into androgen effects on tumor incidence (Tables 2 and 3) or regression (Table 4) as discussed below.

\section{Androgen effects on tumor incidence}

Studies have shown (Tables 2 and 3) that androgen treatment of rodents before the appearance of palpable DMBA, $\mathrm{MCA}$, or $N$-nitroso- $N$-methylurea-induced tumors significantly decreased mammary tumor incidence [15,40-46] and increased latency $[40,46]$.

Androgens (testosterone propionate (TP), unesterified testosterone, DHT) or pro-androgens (DHEA) were generally administered by subcutaneous injection around the time of chemical carcinogen treatment, with the duration of androgen treatment varying from single injection to continuous treatment until tumor(s) developed. As noted previously (see Androgens and the androgen receptor), some androgens can be enzymatically modified to other potent bioactive steroids such as the aromatization of testosterone into $\mathrm{E}_{2}$ and the $5 \alpha$-reduction to DHT, while other androgens may be metabolized to corresponding estrogens or activated or inactivated by $5 \alpha$-reduction. Similarly, DHT can be reduced to 3-diols [47], while the pro-androgen DHEA can be metabolized to testosterone, DHT or $E_{2}$. Nevertheless, despite different androgens being used in these experiments, all of the studies reported that androgens reduced chemically induced mammary tumor incidence (Table 2) and increased tumor latency at certain doses of androgen treatment. These findings imply that the strong, AR-mediated androgen effect on tumor incidence in carcinogen-induced mammary tumors could be via AR-dependent regulation of cell proliferation and/ or CYP-mediated carcinogen activation and formation of DNA adducts as discussed in Chemical carcinogenesis.

The mechanism(s) for androgen-induced inhibition of chemically induced mammary carcinoma still remains unclear. Androgens may inhibit pituitary and ovarian function [48]; however, androgens could also have direct effects because rodent mammary epithelium as well as carcinogen-induced mammary tumors are AR-positive $[49,50]$. This latter interpretation of direct effects is supported by the fact that potent DHT inhibition of the growth of DMBA-induced mammary tumors persists in ovariectomized rats [51].

DMBA-induced tumor incidence has also been examined after neonatal androgenization of female rats (Table 3) [52-57], with androgens first injected between 0 to 5 days after birth and treatment varying from a single injection to continuous treatment until the end of the experiment. Most studies [52-55], but not all [56,57], found that, like peri-pubertal treatments, neonatal androgenization reduced tumor incidence. The protective role of neonatal androgenization could be due to depressed pituitary and ovarian function following neonatal androgen 
Table 2 Androgen effects on tumor incidence (induced by chemical carcinogens)

\begin{tabular}{|c|c|c|c|c|c|}
\hline Reference & Animal model & Type of androgen & Dose $^{a}$ & Duration & Incidence \\
\hline \multicolumn{6}{|c|}{ 7,12-Dimethylbenz(a)anthracene } \\
\hline Briziarelli [40] & SD rats ${ }^{b}$ & TP & $0.01,0.05,0.5,1$ or $1.5 \mathrm{mg}$ daily & 30 days & $\downarrow$ (at doses of 0.5 to $1.5 \mathrm{mg})^{c}$ \\
\hline Briziarelli [41] & SD rats & TP & $0.13,0.26,0.4$ or $10.5 \mathrm{mg}$ daily & 10 days & $\downarrow(0.26$ only) \\
\hline Li and colleagues [42] & SD rats & DHEA & (Not described) & Implant & $\downarrow$ \\
\hline Luo and colleagues [43] & SD rats & DHEA & 5,10 or 20 mg daily & 9 months & $\downarrow$ \\
\hline Kohama and colleagues [44] & Wistar rats & DHEA or TE & $\begin{array}{l}150 \mathrm{mg} / \mathrm{kg} \text { DHEA or } 60 \mathrm{mg} / \mathrm{kg} \\
\text { TE weekly }\end{array}$ & 22 weeks & $\downarrow$ \\
\hline \multicolumn{6}{|l|}{ Methylcholanthrene } \\
\hline Shay and colleagues [15] & Wistar rats & $\mathrm{T}$ & 37 or $75 \mathrm{mg}$ & Implant & $\downarrow$ \\
\hline Shay and colleagues [45] & Wistar rats & $\mathrm{T}$ & $75 \mathrm{mg}$ & Implant & $\downarrow$ \\
\hline \multicolumn{6}{|l|}{$N$-Nitroso- $N$-methylurea } \\
\hline Lubet and colleagues [46] & SD rats & DHEA & $\begin{array}{l}5,24,120,600 \text { or } 2,000 \mathrm{mg} / \mathrm{kg} \\
\text { DHEA in diet }\end{array}$ & 109 days & $\downarrow(600 / 2,000)$ \\
\hline
\end{tabular}

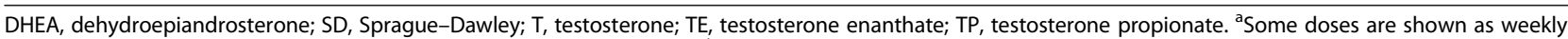
doses calculated based on the dosing regime in the original article. ${ }^{b}$ Female rats unless otherwise specified. ${ }^{c}$ When TP treatment started 10 or 20 days after 7,12-dimethylbenz(a)anthracene but not later.

treatment $[53,54]$ or reduced P4 levels in sexually mature females that could modify the response to carcinogens [55]. This hypothesis is supported by the finding that P4 treatment of neonatally androgenized females increased the DMBA-induced mammary cancer incidence [58]. In addition, neonatal androgenization causes lactational differentiation of the mammary epithelium [52,59] that may modify responses to DMBA.

DMBA alone does not induce mammary tumors in Sprague-Dawley male rats, whereas when $E_{2}$ is coadministered 50\% develop tumors within 26 weeks [38]. This is comparable with our findings in male mice where DMBA caused enlargement of mammary lymph nodes, but not the growth of mammary tumors in either wildtype or AR knockout males for up to 39 weeks [1]. These findings demonstrate that exposure to ovarian hormones, notably the sole bioactive estrogen $\mathrm{E}_{2}$, is necessary to promote carcinogen-induced rodent mammary tumors.

\section{Androgen effects on tumor growth}

Most studies [51,60-79], but not all [16], found that androgen treatment after the appearance of palpable, chemically induced mammary tumors caused tumor regression (Table 4).

Administration of the nonaromatizable androgen drostanolone (2,10,13-trimethyl DHT) propionate $(40 \mathrm{mg} / \mathrm{kg}$, $5 /$ week for 6 weeks) to rats had no effect on DMBAinduced or MCA-induced mammary tumors [16]. Yet both DMBA-induced and MCA-induced mammary tumors regressed following ovariectomy, demonstrating that the tumors remained hormone dependent. One explanation could be the dose dependency of androgen effects, as low dose (12 or $6 \mathrm{mg} / \mathrm{kg}$ weekly) induced tumor regression, consistent with another study using a different DHT analog (2 $\alpha$-methyl DHT) [49], whereas a very high TP dose (210 $\mathrm{mg} / \mathrm{kg}$ weekly) stimulated DMBA-induced tumor growth [61]. These dose dependencies may reflect direct cross-reactivity of very high DHT doses with off-target estrogen or other receptor mechanisms.

\section{Effect of anti-androgens or androgen receptor inactivation on mammary tumors}

The anti-androgen flutamide has been used to investigate the role of androgens in chemical carcinogen-induced

Table 3 Neonatal androgen effects on tumor incidence (induced by chemical carcinogens)

\begin{tabular}{|c|c|c|c|c|c|}
\hline Reference & Animal model & Type of androgen & Dose (mg) & Duration & Incidence \\
\hline \multicolumn{6}{|c|}{ 7,12-Dimethylbenz(a)anthracene } \\
\hline Kovács [52] & Wistar rats $^{\mathrm{a}}$ & TP & 2.5 & Single injection & $\downarrow$ \\
\hline Shellabarger and Soo [53] & SD rats & TP & 1.25 & Single injection & $\downarrow$ \\
\hline Christakos and colleagues [54] & SD rats & TP & 1.25 & Single injection & $\downarrow$ \\
\hline Yoshida and colleagues [55] & SD rats & TP & 1.25 & Daily until the end of the experiment & $\downarrow$ \\
\hline Purnell [56] & LEW/Mai rats & $\mathrm{TP}$ & 1.25 & Single injection & No effect \\
\hline Verhoeven and colleagues [57] & Female and male SD rats & TP & 0.5 & Single injection & No effect \\
\hline
\end{tabular}

SD, Sprague-Dawley; TP, testosterone propionate. ${ }^{a}$ Female rats unless otherwise specified. 
Table 4 Androgen effects on tumor growth (induced by chemical carcinogens)

\begin{tabular}{|c|c|c|c|c|}
\hline Reference & Animal model & Type of androgen & Dose $^{a}$ & Tumor growth \\
\hline \multicolumn{5}{|c|}{ 7,12-Dimethylbenz(a)anthracene (using androgens) } \\
\hline \multirow[t]{2}{*}{ Young and colleagues [60] } & SD rats ${ }^{b}$ & $\mathrm{~T}$ & 1.2 to $6 \mathrm{mg}$ weekly & $\downarrow$ \\
\hline & & DHT & 1.2 to 6 mg weekly & \\
\hline Heise and Gorlich [61] & SD rats & TP & 6 to $180 \mathrm{mg} / \mathrm{kg}$ weekly & $\downarrow$ (low dose only) \\
\hline Teller and colleagues [62] & SD rats & MDTP and TP & Total of $480 \mathrm{mg}$ for 8 weeks & $\downarrow$ \\
\hline Shimkin and colleagues [16] & SD/Wistar rats & $\mathrm{DP}$ & $200 \mathrm{mg}$ weekly for 6 weeks & No effect \\
\hline Teller and colleagues [63] & SD rats & MDTP and TP & 3.75 to 60 mg weekly for 8 weeks & $\downarrow$ \\
\hline Teller and colleagues [64] & SD rats & MDTP & 60 mg weekly for 8 weeks & $\downarrow$ \\
\hline Mobbs [67] & SD rats & $\mathrm{TP}$ & 10 or $50 \mathrm{mg} / \mathrm{kg}$ weekly or a single $60 \mathrm{mg}$ pellet & $\downarrow$ (high dose only) \\
\hline Griswold and Green [68] & SD rats & MDTP and TP & $10 \mathrm{mg} / \mathrm{kg}$ daily for 20 days & $\downarrow$ \\
\hline Briziarelli and colleagues [69] & SD rats & FBTA & 2 or $4 \mathrm{mg}$ daily for 30 days & $\downarrow$ \\
\hline Takahashi and colleagues [70] & SD rats & MDTP and TP & 6 mg weekly & $\downarrow$ \\
\hline Quadri and colleagues [71] & SD rats & $\mathrm{DmP}$ & $0.5 \mathrm{mg}$ daily for 3 weeks & $\downarrow$ \\
\hline Horn and colleagues [72] & Inbred rats & Calsterone & 10 mg daily for 2 to 3 weeks & $\downarrow$ \\
\hline Costlow and colleagues [73] & SD rats & $\mathrm{TP}$ & 8 mg weekly & $\downarrow$ \\
\hline Zava and McGuire [74] & SD rats & $\mathrm{TP}$ & 2.4 mg weekly & $\downarrow$ \\
\hline Teller and colleagues [65] & SD rats & MDTP & 200 mg/kg weekly for 5 weeks & $\downarrow$ \\
\hline Teller and colleagues [66] & SD rats & MDTP & 3 to $100 \mathrm{mg} / \mathrm{kg}$ weekly for 4 weeks & $\downarrow$ (dose dependent) \\
\hline Dauvois and colleagues [51] & SD rats & $\mathrm{DHT}$ & 3 cm silastic implant (30/100, DHT/cholesterol, w/w) & $\downarrow$ \\
\hline Boccuzzi and colleagues [75] & SD rats & DHEA & 4 mg daily for 21 days & $\downarrow$ \\
\hline Boccuzzi and colleagues [76] & SD rats & DHT & $25 \mu \mathrm{g}$ DHT daily for 20 days & $\downarrow$ \\
\hline Gatto and colleagues [77] & SD rats & DHEA & 4 mg daily for 20 days & $\downarrow$ \\
\hline \multicolumn{5}{|c|}{ Methylcholanthrene (using androgens) } \\
\hline Ercoli and Briziarelli [79] & SD rats & DHT or DHT enol ethers & 2 mg daily for 30 days & $\downarrow$ \\
\hline Shimkin and colleagues [16] & SD/Wistar rats & $\mathrm{DP}$ & $200 \mathrm{mg} / \mathrm{kg}$ weekly for 6 weeks & No effect \\
\hline \multicolumn{5}{|c|}{ 7,12-Dimethylbenz(a)anthracene (using anti-androgens) } \\
\hline Spinola and colleagues [78] & SD rats & Flutamide & 10 mg daily for 20 days & $\downarrow$ \\
\hline Boccuzzi and colleagues [76] & SD rats & Flutamide & 2 mg daily for 20 days & $\downarrow$ \\
\hline
\end{tabular}

DHEA, dehydroepiandrosterone; DHT, dihydrotestosterone; DmP, dromostanolone propionate; DP, drostanolone propionate; FBTA, 9a-fluoro-11 $\beta$-hydroxybenzo[d,e] testosterone 17-acetate; MDTP, 2a-methyl-DHT propionate; SD, Sprague-Dawley; T, testosterone; TP, testosterone propionate. ${ }^{a}$ Some doses are shown as weekly doses calculated based on the dosing regime in the original article. ${ }^{\mathrm{b}}$ Female rats unless otherwise specified.

mammary tumors [76,78]. Surprisingly, flutamide markedly inhibited the growth of DMBA-induced mammary tumors in female rats, contrasting with the inhibitory effect of androgens. The most probable mechanism is that flutamide has weak direct partial agonist effects on AR when sufficiently high flutamide doses are applied on a low androgenic background (for example, in female or castrated animals) [80]. Other less likely mechanisms include: inhibition of adrenal steroid production, which is implausible given the rodent adrenal's negligible androgen output [81]; or reduced endogenous P4 secretion [78], due to neuroendocrine effects on pituitary and/or ovarian hormone secretion [82]. The uncertainties reflect the limitations of using solely pharmacological probes to define steroidal molecular mechanisms.
Using an androgen receptor knockout (ARKO) androgen-insensitive female mouse model (expressing a mutated, inactive AR) combined with DMBA chemical carcinogenesis, however, we demonstrated that the onset of palpable mammary tumors was significantly faster in ARKO females compared with wild-type female mice (median time, 22 weeks vs 34 weeks, respectively) [1], supporting the inhibitory role of AR-mediated androgen actions in mammary carcinogenesis. This observation predicts that otherwise healthy women who are heterozygous for the functional and inactive AR alleles (for example, mothers of children with androgen insensitivity) could also be at increased risk of breast cancer, although this prediction remains to be tested. This prediction is also supported by increased breast cancer susceptibility in women with 
reduced AR activity due to longer polymorphic CAG repeats [83]. The relationship between AR CAG repeats and breast cancer susceptibility could be further tested using a humanized mouse model where AR activity is modified [84] by replacing the rodent $A r$ gene with most of the human $A r$ exon 1 CAG repeat length variant [85]. Hence, investigating the relationship between AR CAG repeats and breast cancer susceptibility may provide direct insight into the relationship between AR activity and breast cancer susceptibility in humans. This relationship has been suspected $[83,86]$ but not experimentally explored.

\section{Effect of aromatase inhibitors on mammary tumor growth}

Aromatase inhibitors inhibit mammary tumor growth in rodents $[78,87,88]$. Aromatase inhibitors cause increases in circulating testosterone concentrations with decreased $\mathrm{E}_{2}$ concentrations in both rodents $[78,88]$ and women [89]. Although the protective role of aromatase inhibitors on breast cancer due to reduced $\mathrm{E}_{2}$ concentrations is well established, the role of the concomitant increases in serum testosterone concentration has usually been overlooked, and could be further explored using genetically modified models with altered aromatase expression [90-93]. However, not only may aromatase inhibitors increase circulating endogenous androgen concentrations, but some possess intrinsic androgenic activity by binding to and activating the AR $[78,87]$ - highlighting the limitations of pharmacological blockade of steroidal mechanisms, where blockers or their metabolites may have offtarget effects. The protective role of aromatase inhibitors in breast cancer could therefore also be due to direct androgenic effects. This is supported by the superior efficacy of the aromatase inhibitor letrozole over the ER blocker tamoxifen (lacking AR activation) [94]. Hence, the effectiveness of aromatase inhibitors as breast cancer treatment may involve their largely overlooked direct androgenic effects on tumors, an interpretation that warrants further evaluation.

\section{Androgens and hormonal carcinogenesis}

Proof of the experimental induction of mammary cancer by the pro-estrogen $E_{1}$ as well as $E_{2}$ in the 1940 s was a landmark in the investigation of hormone-dependent breast cancer [95]. In rats, co-administration of testosterone increased latency for the appearance of $E_{1}$-induced palpable tumors, in a dose-dependent manner [96]. In addition, administration of testosterone to rats already bearing $\mathrm{E}_{1}$-induced mammary tumors decreased the tumor area $[96,97]$. These findings further support a protective role of androgens in experimental carcinogenesis, despite the mechanism of tumor induction (carcinogen or hormonally induced). This implies either direct AR-mediated regulation of cell proliferation or perhaps similar mechanisms involving induction of experimental tumors.
In contrast, Noble demonstrated that simultaneous treatment with $E_{1}$ and TP in Noble rats significantly increased the incidence of mammary tumors compared with $E_{1}$ treatment alone [98], further supported by more recent studies [99-101], although high doses of testosterone also reduced the latency of $\mathrm{E}_{2}$-induced tumors [101]. Testosterone may act as an endogenous promoter in estrogen-induced mammary carcinogenesis via stimulation of paracrine secretion of growth factors in mammary glands or oncogenes in mammary cells, rather than through the stimulation of breast cell proliferation [101]. However, the reasons for the contradictory findings on the impact of testosterone on hormone-induced breast cancer remain unknown.

\section{Androgens and spontaneous rodent carcinogenesis}

Specific rat and mouse lines that develop spontaneous mammary tumors have been used to investigate the role of androgens in the incidence of these tumors, as well as their growth as tumor transplants (Table 5). Growth of $80 \%$ of spontaneous mammary tumors was prevented by TP treatment [102], while testosterone or DHT treatment induced significant regression of transplanted tumors [103]. DHT administration to ovariectomized rats caused greater regression of tumor growth, suggesting a direct effect on tumor cells; however, a contributory effect of androgens in reducing ovarian hormone secretion due to negative hypothalamic feedback mechanisms could not be excluded [103].

Most studies [30,102,104-108], but not all [109,110], demonstrated that the treatment of mice with TP or the pro-androgen DHEA before the development of palpable tumors reduced the incidence of tumors in mice (mainly $\mathrm{C} 3 \mathrm{H}$ ). In contrast, postnatal treatment (days 1 to 5) of $\mathrm{SHN}$ or BALB/cfC3H female mice with DHT or testosterone significantly increased mammary tumor incidence when compared with vehicle-treated control groups $[109,110]$. These opposite effects could be related to timing of the androgen exposure, but the significance is still uncertain.

\section{Androgens and genetically modified mouse breast cancer models}

In our studies, androgen-insensitive female mice (global ARKO model) have increased susceptibility to DMBAinduced mammary tumors, which demonstrates direct mammary gland-specific effects of androgens acting via the AR [1]. A study using Cre/LoxP-mediated conditional deletion of the $A r$ allele in mammary epithelium demonstrated that reduced epithelial AR expression also promoted the early onset of Neu (ERBB2) proto-oncogene tumors [32], suggesting that the AR in mammary epithelial cells may have a significant role in AR-dependent protection against experimental breast cancer. Yet transgenic rats 
Table 5 Androgen effects on spontaneous tumor growth/incidence

\begin{tabular}{llllll}
\hline Reference & Mouse/rat & Carcinogen & Dose ${ }^{\text {a }}$ & Duration & Tumor growth/ \\
incidence
\end{tabular}

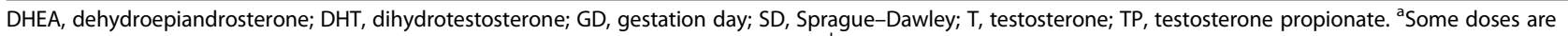
shown as weekly doses calculated based on the dosing regime in the original article. ${ }^{\mathrm{b}}$ Female rats/mice unless otherwise specified.

overexpressing rat ERBB2 in the mammary gland developed mammary tumors only in males and not in females, suggesting that the development of tumors was androgen dependent [111]. This androgen dependency was further supported by findings that orchidectomy prevented male mammary tumor development while DHT treatment restored it. This discrepancy between mouse and rat models targeting the ERBB2 pathway may be due to the fact that the mouse model overexpressed the mutated form of ERBB2 [32], whereas the rat model overexpressed nonmutated ERBB2 [111] and rat tumors were strongly AR-positive while mouse tumors had low AR immunopositivity. While only few studies have so far utilized the ARKO mouse models, in the future these models (both global and cell-specific ARKO) combined with various transgenic experimental breast cancer models may be uniquely enlightening when exploring the cell-specific role of AR as well as the influence of AR-mediated androgen actions on specific carcinogenic pathways.

\section{Discussion and conclusions}

Rodent models have been used to investigate hormonal mechanisms in experimental breast cancer, but the lack of uniformity of findings - in terms of experimental design, species, strain, mechanism of tumor induction, and types of androgens used - renders it difficult to develop an integrated explanatory mechanism. Yet, despite considerable variability in study design, most rodent studies suggest a protective role for androgens at several stages of experimental breast cancer. Nevertheless, a minority suggests that androgens increase, or anti-androgens protect against, experimental breast cancer. The reasons for these discrepancies may provide potentially important clues to unravel the role of androgens in experimental breast cancer. The suggested explanatory framework involves a biphasic effect of androgens with low or moderate doses inducing tumor regression, while higher doses have no or stimulatory effects on tumor growth. The growthpromoting effect at high androgen doses could be via ER-dependent mechanisms: either via enzymatic conversion of aromatizable androgens used or via direct binding of supraphysiological androgen concentrations to the ER.

AR-mediated androgen signaling has recently been suggested to be inhibitory in ER $\alpha$-positive breast cancers, opposing the effect of estrogens, while androgens in the presence of AR may activate the oncogenic properties of $A R$ in ER $\alpha$-negative tumors (reviewed in [2]). This concept is also utilized in the clinical setting, where AR inhibition is considered a potential therapeutic target for ER $\alpha$-negative but not AR-positive breast cancers. The influence of androgens on experimentally induced ER $\alpha$ positive or ER $\alpha$-negative cancers has not been systematically evaluated in rodent studies. This is possibly due to the difficulty in developing estrogen-dependent, ER $\alpha$-positive 
tumors in mice. DMBA has been shown to induce the development of ER $\alpha$-positive tumors in rats [74] and mice [1], and thus could allow for the comparison of tumor progression between ER $\alpha$-positive and ER $\alpha$ negative tumors. Similarly, while ER $\alpha$ status is usually analyzed in experimental breast cancer models, AR expression has not been systematically determined. Much more in-depth analysis of AR expression and the role of AR-mediated androgen action as well as modifying factors is therefore necessary to optimize the opportunity afforded by the role of androgen action at all stages of experimental breast cancer.

These opportunities are being developed with therapies targeted to AR or androgen production involved in recently initiated, empirically motivated clinical trials [112-114]. Interestingly, the anti-androgen bicalutamide showed some treatment efficacy in a phase II clinical trial testing treatment for ER-negative/AR-positive breast cancers (ClinicalTrials.gov NCT00468715) [112]. However, as discussed above regarding anti-androgens in experimental breast cancer, anti-androgens such as bicalutamide can also have agonist properties, demonstrated clinically by a decline in serum prostate-specific antigen following bicalutamide withdrawal [115]. Largely, the mechanisms of androgen actions as well as the modifying factors involved are still not sufficiently well known. More detailed mechanistically oriented experimental work on androgen metabolism, on the mechanisms of androgen action, as well as on modifying/interacting factors for the role of the AR in breast cancer is therefore still needed in order to develop efficient and better targeted androgen therapies.

In conclusion, while androgens are assumed inhibitory and estrogens stimulatory for mammary cell proliferation in experimental settings, it is possible that the ratios of these hormones and/or their respective receptors may regulate the optimal balance in tissue maintenance and if disturbed will lead to pathological/malignant growth. As the $\mathrm{AR}$ is one of the most abundant steroid receptors present in breast cancers, more research is warranted to understand androgen actions via the AR in breast tissue as a regulator for optimal hormonal balance and to provide opportunities for novel therapeutic targets and prognostic biomarkers for this lethal disease.

\section{Abbreviations \\ AR: Androgen receptor; ARKO: Androgen receptor knockout; CYP: Cytochrome P450; DHEA: Dehydroepiandrosterone; \\ DHT: Dihydrotestosterone; DMBA: 7,12-dimethylbenz(a)anthracene; \\ $\mathrm{E}_{1}$ : Estrone; $\mathrm{E}_{2}$ : Estradiol; ER: Estrogen receptor; MCA: Methylcholanthrene; \\ TP: Testosterone propionate.}

\section{Competing interests}

The authors declare that they have no competing interests.

\section{References}

1. Simanainen U, Gao YR, Walters KA, Watson G, Desai R, Jimenez M, Handelsman DJ: Androgen resistance in female mice increases susceptibility to DMBA-induced mammary tumors. Hormones Cancer 2012, 3:113-124.

2. Hickey TE, Robinson JL, Carroll JS, Tilley WD: Minireview: The androgen receptor in breast tissues: growth inhibitor, tumor suppressor, oncogene? Mol Endocrinol 2012, 26:1252-1267.

3. McNamara KM, Yoda T, Takagi K, Miki Y, Suzuki T, Sasano H: Androgen receptor in triple negative breast cancer. J Steroid Biochem Mol Biol 2013, 133:66-76.

4. Nicolas Diaz-Chico B, German Rodriguez F, Gonzalez A, Ramirez R, Bilbao C, Cabrera de Leon A, Aguirre Jaime A, Chirino R, Navarro D, Diaz-Chico JC: Androgens and androgen receptors in breast cancer. J Steroid Biochem Mol Biol 2007, 105:1-15.

5. Weihua Z, Lathe R, Warner M, Gustafsson JA: An endocrine pathway in the prostate, ERbeta, AR, 5alpha-androstane-3beta,17beta-diol, and CYP7B1, regulates prostate growth. Proc Natl Acad Sci U S A 2002, 99:13589-13594.

6. Iwamura M, Abrahamsson PA, Benning CM, Cockett AT, di Sant'Agnese PA: Androgen receptor immunostaining and its tissue distribution in formalin-fixed, paraffin-embedded sections after microwave treatment. J Histochem Cytochem 1994, 42:783-788.

7. Gasparini P, Fassan M, Cascione L, Guler G, Balci S, Irkkan C, Paisie C, Lovat F, Morrison C, Zhang J, Scarpa A, Croce CM, Shapiro CL, Huebner K: Androgen receptor status is a prognostic marker in non-basal triple negative breast cancers and determines novel therapeutic options. PLOS ONE 2014, 9:e88525.

8. Gammon MD, Thompson WD: Polycystic ovaries and the risk of breast cancer. Am J Epidemiol 1991, 134:818-824

9. Tomalik-Scharte D, Maiter D, Kirchheiner J, Ivison HE, Fuhr U, Arlt W: Impaired hepatic drug and steroid metabolism in congenital adrenal hyperplasia due to P450 oxidoreductase deficiency. Eur J Endocrinol 2010, 163:919-924.

10. Medina D: Of mice and women: a short history of mouse mammary cancer research with an emphasis on the paradigms inspired by the transplantation method. Cold Spring Harbor Perspect Biol 2010, 2:a004523.

11. Berenblum I: Carcinogenesis and tumor pathogenesis. In Advances in Cancer Research. Volume 2. Edited by Greenstein JP, Haddow A. New York: Academic Press; 1954:129-175.

12. Stowers SJ, Maronpot RR, Reynolds SH, Anderson MW: The role of oncogenes in chemical carcinogenesis. Environ Health Perspect 1987, 75:81-86.

13. Mao JH, To MD, Perez-Losada J, Wu D, Del Rosario R, Balmain A: Mutually exclusive mutations of the Pten and ras pathways in skin tumor progression. Genes Dev 2004, 18:1800-1805.

14. Yu M, Leav BA, Leav I, Merk FB, Wolfe HJ, Ho SM: Early alterations in ras protooncogene mRNA expression in testosterone and estradiol-17 beta induced prostatic dysplasia of noble rats. Lab Invest 1993, 68:33-44.

15. Shay $H$, Harris C, Gruenstein M: Influence of sex hormones on the incidence and form of tumors produced in male or female rats by gastric instillation of methylcholanthrene. J Natl Cancer Inst 1952, 13:307-331.

16. Shimkin MB, Gropper L, Thatcher D, Gruenstein M: Hormonal treatment of mammary tumors in rats induced by 3-methylcholanthrene (NSC-21970) and 7,12-dimethylbenz(alpha)anthracene (NSC-408823). Cancer Res 1967, 27:1284-1288.

17. Welsch CW: Host factors affecting the growth of carcinogen-induced rat mammary carcinomas: a review and tribute to Charles Brenton Huggins. Cancer Res 1985, 45:3415-3443.

18. Barhoover MA, Hall JM, Greenlee WF, Thomas RS: Aryl hydrocarbon receptor regulates cell cycle progression in human breast cancer cells via a functional interaction with cyclin-dependent kinase 4 . $\mathrm{Mol}$ Pharmacol 2010, 77:195-201.

19. Monostory K, Pascussi JM, Kobori L, Dvorak Z: Hormonal regulation of CYP1A expression. Drug Metab Rev 2009, 41:547-572.

20. Wu Y, Baumgarten SC, Zhou P, Stocco C: Testosterone-dependent interaction between androgen receptor and aryl hydrocarbon receptor induces liver receptor homolog 1 expression in rat granulosa cells. Mol Cell Biol 2013, 33:2817-2828.

21. Borman SM, Christian PJ, Sipes IG, Hoyer PB: Ovotoxicity in female Fischer rats and $\mathrm{B} 6$ mice induced by low-dose exposure to three polycyclic 
aromatic hydrocarbons: comparison through calculation of an ovotoxic index. Toxicol Appl Pharmacol 2000, 167:191-198.

22. Noble RL, Cutts JH: Mammary tumors of the rat: a review. Cancer Res 1959, 19:1125-1139.

23. Russo J, Fernandez SV, Russo PA, Fernbaugh R, Sheriff FS, Lareef HM, Garber J, Russo IH: 17-Beta-estradiol induces transformation and tumorigenesis in human breast epithelial cells. Faseb J 2006, 20:1622-1634.

24. Roy D, Cai Q, Felty Q, Narayan S: Estrogen-induced generation of reactive oxygen and nitrogen species, gene damage, and estrogen-dependent cancers. J Toxicol Environ Health B Crit Rev 2007, 10:235-257.

25. Peters AA, Buchanan G, Ricciardelli C, Bianco-Miotto T, Centenera MM, Harris JM, Jindal S, Segara D, Jia L, Moore NL, Henshall SM, Birrell SN, Coetzee GA, Sutherland RL, Butler LM, Tilley WD: Androgen receptor inhibits estrogen receptor-alpha activity and is prognostic in breast cancer. Cancer Res 2009, 69:6131-6140.

26. Kojima M, Sekimoto M, Degawa M: Androgen-mediated down-regulation of CYP1A subfamily genes in the pig liver. J Endocrinol 2010, 207:203-211.

27. Aldaz CM, Liao QY, LaBate M, Johnston DA: Medroxyprogesterone acetate accelerates the development and increases the incidence of mouse mammary tumors induced by dimethylbenzanthracene. Carcinogenesis 1996, 17:2069-2072.

28. Kemppainen JA, Langley E, Wong Cl, Bobseine K, Kelce WR, Wilson EM: Distinguishing androgen receptor agonists and antagonists: distinct mechanisms of activation by medroxyprogesterone acetate and dihydrotestosterone. Mol Endocrinol 1999, 13:440-454.

29. Burek JD: Pathology of Aging Rats. Boca Raton, Florida: CRC Press; 1978.

30. Nathanson IT, Andervont HB: Effect of testosterone propionate on development and growth of mammary carcinoma in female mice. Exp Biol Med 1939, 40:421-422.

31. Darbre P, Page M, King RJ: Androgen regulation by the long terminal repeat of mouse mammary tumor virus. Mol Cell Biol 1986, 6:2847-2854.

32. Hodgson MC, Vanostran G, Alghamdi S, Poppiti RJ, Agoulnik Al, Agoulnik IU: Reduced androgen receptor expression accelerates the onset of ERBB2 induced breast tumors in female mice. PLOS ONE 2013, 8:e60455.

33. Martin AM, Weber BL: Genetic and hormonal risk factors in breast cancer. J Natl Cancer Inst 2000, 92:1126-1135.

34. Chlebowski RT, Kuller LH, Prentice RL, Stefanick ML, Manson JE, Gass M, Aragaki AK, Ockene JK, Lane DS, Sarto GE, Rajkovic A, Schenken R, Hendrix SL, Ravdin PM, Rohan TE, Yasmeen S, Anderson G, WHI Investigators: Breast cancer after use of estrogen plus progestin in postmenopausal women. N Engl J Med 2009, 360:573-587.

35. Cardiff RD: Validity of mouse mammary tumour models for human breast cancer: comparative pathology. Microsc Res Technique 2001, 52:224-230.

36. Hennessy BT, Krishnamurthy S, Giordano S, Buchholz TA, Kau SW, Duan Z, Valero V, Hortobagyi GN: Squamous cell carcinoma of the breast. $J$ Clin Oncol 2005, 23:7827-7835.

37. Russo J, Gusterson BA, Rogers AE, Russo IH, Wellings SR, van Zwieten MJ: Comparative study of human and rat mammary tumorigenesis. Lab Invest 1990, 62:244-278.

38. Nandi S, Guzman RC, Yang J: Hormones and mammary carcinogenesis in mice, rats, and humans: a unifying hypothesis. Proc Natl Acad Sci U S A 1995, 92:3650-3657.

39. Herschkowitz JI, Simin K, Weigman VJ, Mikaelian I, Usary J, Hu Z, Rasmussen KE, Jones LP, Assefnia S, Chandrasekharan S, Backlund MG, Yin Y, Khramtsov Al, Bastein R, Quackenbush J, Glazer Rl, Brown PH, Green JE, Kopelovich L, Furth PA, Palazzo JP, Olopade OI, Bernard PS, Churchill GA, Van Dyke T, Perou CM: Identification of conserved gene expression features between murine mammary carcinoma models and human breast tumors. Genome Biol 2007, 8:R76.

40. Briziarelli G: Effects of dosage and time of administration of testosterone propionate on 7,12-dimethylbenzanthracene mammary carcinogenesis in the rat. $Z$ Krebsforsch 1965, 66:517-522.

41. Briziarelli $\mathrm{G}$ : Effects of hormonal pre-treatment against the induction of mammary tumors by 7,12-dimethylbenz[a]anthracene in rats. $Z$ Krebsforsch 1966, 68:217-223.

42. Li S, Yan X, Belanger A, Labrie F: Prevention by dehydroepiandrosterone of the development of mammary carcinoma induced by 7,12-dimethylbenz (a)anthracene (DMBA) in the rat. Breast Cancer Res Treat 1993, 29:203-217.

43. Luo S, Labrie C, Belanger A, Labrie F: Effect of dehydroepiandrosterone on bone mass, serum lipids, and dimethylbenz(a)anthracene-induced mammary carcinoma in the rat. Endocrinology 1997, 138:3387-3394.
44. Kohama T, Terada S, Suzuki N, Inoue M: Effects of dehydroepiandrosterone and other sex steroid hormones on mammary carcinogenesis by direct injection of 7,12-dimethylbenz(a) anthracene (DMBA) in hyperprolactinemic female rats. Breast Cancer Res Treat 1997, 43:105-115.

45. Shay $H$, Gruenstein M, Kessler W: Experimental mammary adenocarcinoma of rats: some considerations of methyl-cholanthrene dosage and hormonal treatment. J Natl Cancer Inst 1961, 27:503-513.

46. Lubet RA, Gordon GB, Prough RA, Lei XD, You M, Wang Y, Grubbs CJ, Steele VE, Kelloff GJ, Thomas CF, Moon RD: Modulation of methylnitrosoureainduced breast cancer in Sprague Dawley rats by dehydroepiandrosterone: dose-dependent inhibition, effects of limited exposure, effects on peroxisomal enzymes, and lack of effects on levels of Ha-Ras mutations. Cancer Res 1998, 58:921-926.

47. Bartsch W, Klein H, Schiemann U, Bauer HW, Voigt KD: Enzymes of androgen formation and degradation in the human prostate. Ann N Y Acad Sci 1990, 595:53-66

48. Huggins C, Mainzer K, Briziarelli G: Molecular structure of steroids and phenanthrene derivatives related to growth of transplanted mammary tumors. Recent Prog Horm Res 1958, 14:77-87. discussion 88-93.

49. Peters AA, Ingman WV, Tilley WD, Butler LM: Differential effects of exogenous androgen and an androgen receptor antagonist in the peri- and postpubertal murine mammary gland. Endocrinology 2011, 152:3728-3737.

50. Cheung SY, Yuen MT, Choi HL, Cheng HK, Huang Y, Chen S, Chan FL: An expression study of hormone receptors in spontaneously developed, carcinogen-induced and hormone-induced mammary tumors in female Noble rats. Int J Oncol 2003, 22:1383-1395.

51. Dauvois S, Li SM, Martel C, Labrie F: Inhibitory effect of androgens on DMBA-induced mammary carcinoma in the rat. Breast Cancer Res Treat 1989, 14:299-306.

52. Kovacs K: Effect of androgenization on the development of mammary tumors in rats induced by the oral adminstration of 9,10-dimethyl-1,2benzanthracene. Br J Cancer 1965, 19:531-537.

53. Shellabarger CJ, Soo VA: Effects of neonatally administered sex steroids on 7,12-dimethylbenz(a)anthracene-induced mammary neoplasia in rats. Cancer Res 1973, 33:1567-1569.

54. Christakos S, Sinha D, Dao TL: Neonatal modification of endocrine functions and mammary carcinogenesis in the rat. Br J Cancer 1976, 34:58-63.

55. Yoshida H, Kadota A, Fukunishi R, Matsumoto K: Induction of mammary dysplasia and mammary carcinoma in neonatally androgenized female rats by 7,12-dimethylbenz[a]anthracene. J Natl Cancer Inst 1980, 64:1 105-1112.

56. Purnell DM: The effects of neonatal androgenization on mammary gland mitotic rate and susceptibility of carcinogen-induced mammary dysplastigenesis and tumorigenesis in LEW/Mai rats. Am J Pathol 1980, 99:463-474.

57. Verhoeven G, Vandoren G, Heyns W, Kuhn ER, Janssens JP, Teuwen D, Goddeeris P, Lesaffre E, De Moor P: Incidence, growth and oestradiolreceptor levels of 7, 12-dimethylbenz (alpha) anthracene-induced mammary tumours in rats: effects of neonatal sex steroids and oestradiol implants. J Endocrinol 1982, 95:357-368.

58. Yoshida H, Fukunishi R, Kato Y, Matsumoto K: Progesterone-stimulated growth of mammary carcinomas induced by 7,12-dimethylbenz[a] anthracene in neonatally androgenized rats. J Natl Cancer Inst 1980, 65:823-828.

59. Dao TL: Mammary tumorigenesis in female rats receiving androgen neonatally. Proc Am Assoc Cancer Res 1966, 7:16.

60. Young S, Baker RA, Helfenstein JE: The effects of androgens on induced mammary tumours in rats. Br J Cancer 1965, 19:155-159.

61. Heise E, Gorlich M: Growth and therapy of mammary tumours induced by 7,12-dimethylbenzanthracene in rats. Br J Cancer 1966, 20:539-545.

62. Teller MN, Stock CC, Bowie M: Effects of 17-alpha-thioestradiol, 2 estradiol analogs, and 2 androgens on 7,12-dimethylbenz[a]anthracene-induced rat mammary tumors. Cancer Res 1966, 26:2329-2333.

63. Teller MN, Kaufman RJ, Stock CC, Bowie M: Criteria for evaluating hormones in the 7,12-dimethylbenz[a]-anthracene-induced mammary tumor-rat experimental chemotherapy system. Cancer Res 1968, 28:368-371

64. Teller MN, Kaufman RJ, Bowie M, Stock CC: Influence of estrogens and endocrine ablation on duration of remission produced by ovariectomy 
or androgen treatment of 7,12-dimethylbenz(a)anthracene-induced rat mammary tumors. Cancer Res 1969, 29:349-352.

65. Teller MN, Stock CC, Hellman L, Mountain IM, Bowie M, Rosenberg BJ, Boyar RM, Budinger JM: Comparative effects of a series of prolactin inhibitors, 17beta-estradiol and 2alpha-methyldihydrotestosterone propionate, on growth of 7,12-dimethylbenz(a)anthracene-induced rat mammary carcinomas. Cancer Res 1977, 37:3932-3938.

66. Teller MN, Stock CC, Bowie M, Chou TC, Budinger JM: Therapy of 7,12dimethylbenz(a)anthracene-induced rat mammary carcinomas with combinations of 5-fluorouracil and 2 alpha-methyldihydrotestosterone propionate. Cancer Res 1982, 42:4408-4412.

67. Mobbs BG: The effect of testosterone treatment on the uptake of $[3 \mathrm{H}]$ oestradiol-17 beta by dimethylbenzanthracene-induced rat mammary tumours. J Endocrinol 1970, 48:293-294.

68. Griswold DP Jr, Green CH: Observations on the hormone sensitivity of 7,12-dimethylbenz(alpha)anthracene-induced mammary tumors in the Sprague-Dawley rat. Cancer Res 1970, 30:819-826.

69. Briziarelli G, Castelli P, Vitali R, Gardi R: 9a-Fluoro-11ß-hydroxybenzo [d, e] testosterone 17-acetate. A modified steroid highly active on DMBAinduced mammary tumors in rats. Experientia 1972, 29:618-619.

70. Takahashi T, Nakamura T, Majima S: Effect of ovariectomy and androgen on the growth of mammary tumors induced by 7,12-dimethylbenz (alpha)-anthracene in rats. Jpn J Surg 1973, 3:229-236.

71. Quadri SK, Kledzik GS, Meites J: Counteraction by prolactin of androgeninduced inhibition of mammary tumor growth in rats. J Natl Cancer Inst 1974, 52:875-878

72. Horn H, Erlichman I, Levij IS: Anti-tumour efficacy of calusterone against DMBA-induced rat mammary adenocarcinoma in vivo and in organ culture. Br J Cancer 1976, 33:336-341.

73. Costlow ME, Buschow RA, McGuire WL: Prolactin receptors and androgen-induced regression of 7,12-dimethylbenz(a)anthracene-induced mammary carcinoma. Cancer Res 1976, 36:3324-3329.

74. Zava DT, McGuire WL: Estrogen receptors in androgen-induced breast tumor regression. Cancer Res 1977, 37:1608-1610.

75. Boccuzzi G, Aragno M, Brignardello E, Tamagno E, Conti G, Di Monaco M, Racca S, Danni O, Di Carlo F: Opposite effects of dehydroepiandrosterone on the growth of 7,12-dimethylbenz(a)anthracene-induced rat mammary carcinomas. Anticancer Res 1992, 12:1479-1483.

76. Boccuzzi G, Tamagno E, Brignardello E, Di Monaco M, Aragno M, Danni O: Growth inhibition of DMBA-induced rat mammary carcinomas by the antiandrogen flutamide. J Cancer Res Clin Oncol 1995, 121:150-154

77. Gatto V, Aragno M, Gallo M, Tamagno E, Martini A, Di Monaco M, Brignardello $E$, Boccuzzi G: Dehydroepiandrosterone inhibits the growth of DMBA-induced rat mammary carcinoma via the androgen receptor. Oncol Rep 1998, 5:241-243.

78. Spinola PG, Marchetti B, Merand Y, Belanger A, Labrie F: Effects of the aromatase inhibitor 4-hydroxyandrostenedione and the antiandrogen flutamide on growth and steroid levels in DMBA-induced rat mammary tumors. Breast Cancer Res Treat 1988, 12:287-296.

79. Ercoli A, Briziarelli G: Effect of enol-ether derivatives of dihydrotestosterone on 3-methylcholanthrene-induced rat mammary carcinoma. J Natl Cancer Inst 1961, 27:1173-1187.

80. Nguyen TV, Yao M, Pike CJ: Flutamide and cyproterone acetate exert agonist effects: induction of androgen receptor-dependent neuroprotection. Endocrinology 2007, 148:2936-2943.

81. van Weerden WM, Bierings HG, van Steenbrugge GJ, de Jong FH, Schroder FH: Adrenal glands of mouse and rat do not synthesize androgens. Life SCi 1992, 50:857-861.

82. Di Monaco M, Brignardello E, Leonardi L, Gatto V, Gallo M, Pizzini A, Boccuzzi G: The antiandrogen flutamide inhibits growth of mcf-7 human breast-cancer cell-line. Int J Oncol 1993, 2:653-656.

83. Buchanan G, Yang M, Cheong A, Harris JM, Irvine RA, Lambert PF, Moore NL, Raynor M, Neufing PJ, Coetzee GA, Tilley WD: Structural and functional consequences of glutamine tract variation in the androgen receptor. Hum Mol Genet 2004, 13:1677-1692.

84. Simanainen U, Brogley M, Gao YR, Jimenez M, Harwood DT, Handelsman DJ, Robins DM: Length of the human androgen receptor glutamine tract determines androgen sensitivity in vivo. Mol Cell Endocrinol 2011, 342:81-86.

85. Albertelli MA, Scheller A, Brogley M, Robins DM: Replacing the mouse androgen receptor with human alleles demonstrates glutamine tract length-dependent effects on physiology and tumorigenesis in mice. Mol Endocrinol 2006, 20:1248-1260.

86. Yu H, Bharaj B, Vassilikos EJ, Giai M, Diamandis EP: Shorter CAG repeat length in the androgen receptor gene is associated with more aggressive forms of breast cancer. Breast Cancer Res Treat 2000, 59:153-161.

87. Zaccheo T, Di Salle E: Effect of the irreversible aromatase inhibitor FCE 24304 on DMBA-induced mammary tumors in ovariectomized rats treated with testosterone. Cancer Chemother Pharmacol 1989, 25:95-98.

88. Abul-Hajj YJ: The effect of the aromatase inhibitor, 4-(phenylthio)-4androstene-3,17-dione, on dimethylbenz(A)anthracene-induced rat mammary tumors. J Steroid Biochem 1989, 34:439-442.

89. Geisler J, Haynes B, Anker G, Dowsett M, Lonning PE: Influence of letrozole and anastrozole on total body aromatization and plasma estrogen levels in postmenopausal breast cancer patients evaluated in a randomized, cross-over study. J Clin Oncol 2002, 20:751-757.

90. Fisher $\mathrm{CR}$, Graves KH, Parlow AF, Simpson ER: Characterization of mice deficient in aromatase (ArKO) because of targeted disruption of the cyp19 gene. Proc Natl Acad Sci U S A 1998, 95:6965-6970.

91. Jones ME, Thorburn AW, Britt KL, Hewitt KN, Wreford NG, Proietto J, Oz OK Leury BJ, Robertson KM, Yao S, Simpson ER: Aromatase-deficient (ArKO) mice have a phenotype of increased adiposity. Proc Natl Acad Sci U S A 2000, 97:12735-12740.

92. Tekmal RR, Ramachandra N, Gubba S, Durgam VR, Mantione J, Toda K, Shizuta Y, Dillehay DL: Overexpression of int-5/aromatase in mammary glands of transgenic mice results in the induction of hyperplasia and nuclear abnormalities. Cancer Res 1996, 56:3180-3185.

93. Li X, Warri A, Makela S, Ahonen T, Streng T, Santti R, Poutanen M: Mammary gland development in transgenic male mice expressing human P450 aromatase. Endocrinology 2002, 143:4074-4083.

94. Regan MM, Neven P, Giobbie-Hurder A, Goldhirsch A, Ejlertsen B, Mauriac L, Forbes JF, Smith I, Lang I, Wardley A, Rabaglio M, Price KN, Gelber RD, Coates AS, Thürlimann B, BIG 1-98 Collaborative Group; International Breast Cancer Study Group (IBCSG): Assessment of letrozole and tamoxifen alone and in sequence for postmenopausal women with steroid hormone receptor-positive breast cancer: the BIG 1-98 randomised clinical trial at 8.1 years median follow-up. Lancet Oncol 2011, 12:1101-1108.

95. Cramer W: The hormonal aetiology of breast cancer. Am J Cancer 1940, 38:463-472.

96. Cutts JH: Estrone-induced mammary tumors in the rat: II. Effect of alterations in the hormonal environment on tumor induction, behavior, and growth. Cancer Res 1964, 24:1124-1130.

97. Cutts $\mathrm{JH}$ : Unusual response to androgen of estrogen-dependent mammary tumors. J Nat/ Cancer Inst 1969, 42:485-488.

98. Noble RL: A new characteristic transplantable type of breast carcinoma in $\mathrm{Nb}$ rats following combined estrogen-androgen treatment. Proc Am Assoc Cancer Res 1976, 17:221.

99. Liao DZ, Pantazis CG, Hou X, Li SA: Promotion of estrogen-induced mammary gland carcinogenesis by androgen in the male Noble rat: probable mediation by steroid receptors. Carcinogenesis 1998, 19:2173-2180.

100. Xie B, Tsao SW, Wong YC: Sex hormone-induced mammary carcinogenesis in female noble rats: the role of androgens. Carcinogenesis 1999, 20:1597-1606.

101. Xie B, Tsao SW, Wong YC: Induction of high incidence of mammary tumour in female Noble rats with a combination of 17beta-oestradiol and testosterone. Carcinogenesis 1999, 20:1069-1078.

102. Heiman J: The effect of androgens and estrogens on spontaneous benign mammary tumors in the rat. Am J Cancer 1940, 40:343-354.

103. Huggins C, Mainzer K: Hormonal influences on mammary tumors of the rat. II. Retardation of growth of a transplanted fibroadenoma in intact female rats by steroids in the androstane series. J Exp Med 1957, 105:485-500.

104. Jones EE: The effect of testosterone propionate on mammary tumors in mice of the C3H strain. Cancer Res 1941, 1:787-789.

105. Lacassagne A, Raynaud A: Sur le mechanisme d'une action preventive de la testosterone sur le carcinome mammaire de la souris. Compt Rend Soc Biol 1939, 131:586.

106. Loeser AA: Mammary carcinoma response to implantation of male hormone and progesterone. The Lancet 1941, 238:698-700.

107. Schwartz AG: Inhibition of spontaneous breast cancer formation in female $\mathrm{C} 3 \mathrm{H}(\mathrm{Avy} / \mathrm{a})$ mice by long-term treatment with dehydroepiandrosterone. Cancer Res 1979, 39:1129-1132. 
108. Heiman J: Effect of testosterone propionate on the adrenals and on the incidence of mammary cancer in the RIII strain of mice. Cancer Res 1944, 4:31-34.

109. Yanai R, Nagasawa H, Mori T, Nakajima Y: Long-term effects of perinatal exposure to 5 alpha-dihydrotestosterone on normal and neoplastic mammary development in mice. Endocrinol Jpn 1981, 28:231-234.

110. Mori T, Bern HA, Mills KT, Young PN: Long-term effects of neonatal steroid exposure on mammary gland development and tumorigenesis in mice. J Natl Cancer Inst 1976, 57:1057-1062.

111. Watson PA, Kim K, Chen KS, Gould MN: Androgen-dependent mammary carcinogenesis in rats transgenic for the Neu proto-oncogene. Cancer Cell 2002, 2:67-79.

112. Gucalp A, Tolaney S, Isakoff SJ, Ingle JN, Liu MC, Carey LA, Blackwell K, Rugo H, Nabell L, Forero A, Stearns V, Doane AS, Danso M, Moynahan ME, Momen LF, Gonzalez JM, Akhtar A, Giri DD, Patil S, Feigin KN, Hudis CA Traina TA, Translational Breast Cancer Research Consortium (TBCRC 011): Phase II trial of bicalutamide in patients with androgen receptor-positive, estrogen receptor-negative metastatic breast cancer. Clin Cancer Res 2013, 19:5505-5512.

113. Cummings SR, Ettinger B, Delmas PD, Kenemans P, Stathopoulos V, Verweij P, Mol-Arts M, Kloosterboer L, Mosca L, Christiansen C, Bilezikian J, Kerzberg EM, Johnson S, Zanchetta J, Grobbee DE, Seifert W, Eastell R, LIFT Trial Investigators: The effects of tibolone in older postmenopausal women. N Engl J Med 2008, 359:697-708.

114. ClinicalTrials.gov [https://clinicaltrials.gov/]

115. Small EJ, Carroll PR: Prostate-specific antigen decline after casodex withdrawal: evidence for an antiandrogen withdrawal syndrome. Urology 1994, 43:408-410.

doi:10.1186/s13058-014-0483-x

Cite this article as: Choi et al:: The role of androgens in experimental rodent mammary carcinogenesis. Breast Cancer Research 2014 16:483. 